\title{
A Case for A Dogme "Lite" EFL Teaching Approach in Kurdistan
}

\author{
${ }^{1}$ Nicholas Rion, ${ }^{2}$ Karwan Kakabra Kakamad, ${ }^{3}$ Abdulfatah Hasan Fatah \\ Soran University, Faculty of Arts, Psychology Department, Iraq \\ zydeconick@gmail.com, Karwan.kakamad@soran.edu.iq, abdulfatah.fatah@soran.edu.iq
}

\begin{abstract}
This critical review looks at the present state of ESL/EFL activities in the Kurdistan region of Iraq, with particular attention to the English speaking abilities of students enrolled in English Medium Instruction (EMI) courses in the region's 13 universities, and calls for the consideration of "Dogme" types of communicative language curricula. The critique, based in large part of a recent survey by the British Council, clearly shows that most college freshmen entering EMI classrooms are not adequately prepared to meet the challenges and rigor of studying in the English language. As a consequence, the paper offers a background about the theories and ideas of an alternative communicative language pedagogy known as Dogme. The critique reviews the ideas of Dogme founder Scott Thornbury and provides both a rationale and four-point plan about how a "Dogme Lite" type of curriculum may be introduced into the present English language curriculums used in public schools in the region.
\end{abstract}

Keywords: Lite, EFL teaching approach, English medium instruction

\section{Introduction}

Dancing in the Dark: In the February-March 2000 edition of the bi-monthly newsletter of the International Association of Teachers of English as a Foreign Language(Thornbury, 2000)the internationally recognized academic and trailblazing EFL teacher Scott Thornbury penned his now famous manifesto "A Dogme for EFL." Inspired in large part by the filmmaking movement Dogme 95 which sought to "cleanse" contemporary cinema of its obsession with technical trickery and superficiality Thornbury called for a similar movement in the EFL community. He wrote, "That it is high time Dogme-type principles were applied to the [EFL] classroom." Like the leaders of the Dogme 95 movement Danish film directors Lars von Trier and Thomas Vinterberg, Thornbury believed that in much the same way that modern filmmaking had been comprised, ESL teaching methodologies and pedagogy had also been bastardized and "hijacked" by a "materials over-load, or by Obsessive Grammar Syndrome (OSG) (Thornbury, 2000)." (Thornbury, Dogme: Dancing in the Dark, 2005)At that time Thornbury wrote that contemporary EFL suffered from "an embarrassment of complementary riches in the form of videos, CD-ROMS, photocopiable resource packs, pull-out word lists, and even websites," not to mention a host of other supplementary materials, that needed to be cut back, if not purged in an effort to return to the fundamentals of teaching.

For the experienced and reforming Thornbury and his compatriot Neil Forrest, it was time to get back to the basics of teaching and the similarities between the Dogme 95 movement and the reforms the two envisioned for modern day EFL teaching could not be ignored. In the 2000 article, Thornbury chronicles their frustrations and the simple basic rules that the two proposed to get EFL back on track. First among these strictures (edicts) was that if the language lesson did not include real language usage then its "usefulness" should be questioned, if not interrogated. In fact, for Thornbury and Forrest real talking had to form the core of the lesson and in much the same way that the revolutionary educational thinker Paulo Freire imagined the ideal relationship between students and teachers as one sharing an equal footing and mutual respect, teachers had to talk not at their students, but with them. Thornbury wrote, "No posturing was allowed." Also central to the Dogme EFL vision was a stripping down, if not a complete rejection of photocopies and texts unless carefully prescribed, and relegating grammar presentations to a 5-minute slot at a time and place that had relevance and meaning for the students involved in the lesson. For the pair, this meant that "no recorded listening material should be introduced into class," unless that listening material was the actual recorded voices and conversations of the students engaged in pair dialogues or group conversations. And, like the stripped-down technology free filmmaking of Dogme 95 grounded in actual place and experiences relevant to the real world, another central Dogme EFL tenant was that real language learning takes place in the "here and now" and has to address the relevant concerns and issues of the people in the world. Not, issues contrived in textbooks with tales from far off lands and alien worldviews of little or no meaning to the students involved in 
the process. Thornbury was specific. He wrote, "No methodological structures should interfere with, nor inhibit, the free flow of participant-driven input, output, and feedback."

In the immediate years after Thornbury published his "Manifesto" Dogme language teaching sparked both a considerable amount of interest within the EFL/ESL teaching community, as well as a considerable amount of criticism and derision. At one early point in 2005 Thornbury's then-popular online blog had over 300 regular contributors and hosted nearly 7,000 posts. According to Thornbury out of these initial conversations several generalized principles seemed to emerge which most of the budding "dogmatists" held in common. Thornbury summarized these in his 2005 article "Dogme: Dancing in the Dark" (Thornbury, Dogme: Dancing in the Dark, 2005)as follows:

- Materials-mediated teaching is the "scenic" route to learning, but the direct route is located in the interactivity between teachers and learners and between the learners themselves.

- The content most likely to engage learners and to trigger learning processes is that which is already there, supplied by the "people in the room."

- Learning is a social and dialogic process, where knowledge is co-constructed rather than "transmitted" or imported from teacher/course book to learner.

- Learning can be mediated through talk, especially talk that is shaped and supported (i.e. scaffolded) by the teacher.

- Rather than being acquired, language (including grammar) emerges: it is an organic process that occurs given the right conditions.

- The teacher's primary function, apart from promoting the kind of classroom dynamic which is conducive to a dialogic and emergent pedagogy, is to optimize language learning affordances, by, for example, directing attention to features of the emergent language.

- Providing space for the learner's voice means accepting that the learner's beliefs, knowledge, experiences, concerns, and desire are valid content in the language classroom.

- Freeing the classroom for third-party, imported materials empowers both teachers and learners.

- Texts, when used, should have relevance for the learner, for both their learning and user contexts.

- Teacher and learners need to unpack the ideological baggage associated with EFL materials-to become critical users of such texts.

Outside Looking in: Now, nearly 20 years since Dogme's inception interest in the movement seems to have waxed and waned to some extent, no doubt, due in large part to the economic concerns and influence of textbook publishers and the private and public institutions aligned to their pedagogies and that ply their wares. Not to mention the many university programs that offer "professional" secondary degrees in Teaching English as a Second Language (TESL) that routinely omit any mention or discussion of the Dogme Phenomenon and the TESL textbooks designed for these programs that also make the same omissions. Moreover, the role and focus of testing giants like TOEFL, ILETS, and Pearson with all that that focus may entail, including their power over the general direction of "official EFLdom", cannot be overlooked for their collective role in diminishing the potential influence and change that "Unplugged/Dogme" could ultimately mean for this multi-billion dollars a year industry's bottom line. But, this is a topic for a later discussion.

Although Thornbury and another colleague Luke Meddings co-authored the book Teaching Unplugged: Dogme in English Teaching(Thornbury L. M., 2009)in 2009 in an effort to articulate both theory and practice and provide some insights into their revolutionary pedagogy, many of the blog sites and web-pages once devoted to the "Dogme ELT" movement have gone silent or ceased altogether. This is not to say, however, that there are still not some relatively current YouTube videos or online discussions in various forums like the EFL Magazine about Thornbury and Medding's "Unplugged" approach or important articles like the recent 2016 study by Abdullah Coskun "Dogme ELT: What do teachers and students think?" (Coskun, 2016) or an earlier 2015 work "A Critique on Dogme ELT" by D.R. Rahul (Rahul, 2015). If anything, the findings of these two recent studies should continue to fuel interest into the "Unplugged/Dogme" movement and consequently should be required reading for anyone interested in learning more about this important alternative to "traditional" text and grammar heavy teaching methods and the thousands of programs around the world tethered to these curriculums. 
Unfortunately, one such area of the world that is generally "tethered" to various Western-centric texts and grammar heavy pedagogies is the largely autonomous Kurdistan region of Iraq where an estimated 5.5 million plus people live and where interest and investment in EFL are at an all-time high. Despite this region's long, troubled and often time's tragic history it has enjoyed a remarkable period of relative peace and prosperity when compared to its southern Iraqi neighbors even during the most recent wars with ISIS beginning in 2014 until the present writing. In particular, since 2005 the number of universities in the region has grown to 13 and according to a recent British Council survey(Borg, 2015) there were a total of 107,486 undergraduate students enrolled in a plethora of academic programs during the 2014-15 school years.

As noted in the British Council report an increasing number of these institutions have implemented and are presently expanding English-medium instruction (EMI) which is the system that uses English as the "primary medium of instruction" in classrooms where English is not the native language of the majority of students. According to the survey all 13 of Kurdistan's universities use EMI to some extent ranging from a low of 10\% of the classes at Soran University to $75 \%$ of the courses at the Sulaimani Polytechnic University, with a high of $100 \%$ of the coursework at Hawler Medical University in Erbil. Moreover, for the purposes of this critique, it is important to point out that for nearly a generation all Kurdish school children receive regular weekly classroom instruction in English from their first year through grade 12. In effect, this would mean that most of today's graduating high school seniors, before entering the university, have completed 12 years of English classes and attended approximately 850 hours of EFL instruction. In addition, the study adds that the Kurdish Ministry of Higher Education and Scientific Research (MHESR) further mandates that all incoming college freshmen receive an additional 2 hours of English instruction each week during their first year at the university.

With this said, one might expect that incoming Kurdish college students would be well on their way to successfully enter EMI classrooms and be able to meet the demands and challenges of studying and working in the English language. However, according to the university professors teaching these EMI classes surveyed by the British Council the vast majority of them believed that their students' levels of English (typically beginner or elementary) were inadequate for the purposes of academic study in English. This raises the fundamental question of; "Why is this the case?" And, for outside viewers like myself, with a little bit of knowledge and experience with the "tenants" of Dogme/Unplugged and the writings and videos of Scott Thornbury and others, as well as some practical experience teaching EFL in Kurdistan, to question the existing system's efficacy. Moreover, understanding the failures and challenges of current EMI practice in Kurdistan's many universities may help inform some of the changes that need to be made not only at the university level, but perhaps more importantly at the elementary and high school levels regarding English language instruction.

Trying to Understand the Problem: The British Council survey reports several reasons for the problems facing EMI teaching and its practitioners. Among the long laundry list of challenges for EMI in Kurdistan reported by many participants is that there is a substantial amount of resistance on the part of students to being taught in this target language. Simply put, according to one EMI teacher/respondent, "The students do not want me to speak English" (Borg, 2015, p. 22) and another teacher of Computer Technology said, "Sometimes my students asked me, why we should study our lecture in English?" This resistance in large part leads to a serious lack of student motivation which the survey chronicles in some detail. One Social Work lecturer noted, "Most students have no motivation to learn...most students in our department are there against their choices (choosing fields they wish to study) (Borg, 2015, p. 23)." Another respondent said, "Also students generally do not have the desire to learn and improve not only the language but also the knowledge." Another teacher of Media studies was much more blunt writing "The students are not willing to learn English."

Another challenge detailed in the report by a majority of the respondents was a large number of students in their classes. One lecturer noted, "The classes are very crowded, the average of a group number is between 50-60 student [s]." An Information and Library Technologies instructor observed, "Big class size: having 75 students in an English class is a disaster. How can I have all my students participate in 45-minute lecture?" The desperation over this overcrowding problem is clearly evidenced in the response of one Surveying instructor who writes, "Owing to the fact that there are so many students in one class, I cannot elucidate 
everything I utter for the individuals and it feels bad knowing some students have not got the message (Borg, 2015, p. 23)." This overcrowding of classes is an international phenomenon which has many causes and unfortunately, in this age of globalizing and privatizing education has few easy solutions at the present time (Meador, 2016). However, to ignore its impact on the state of present EMI and EFL/ESL activities in Kurdistan is to invite further disaster and any consideration of educational reforms must place finding "innovative" solutions for overcrowded classrooms at the center of the discussion.

Besides the limited student proficiency in English of those enrolled in EMI classes acknowledged in the British Council report are the limitations many lecturers highlighted about their own English abilitiesespecially their spoken English expertise. Although a large majority of $91.7 \%$ of the native Kurdish speaking EMI instructors surveyed said they were confident in their abilities to teach in English, on another question almost the same numbers revealed that they would like to improve both their spoken and written English. Moreover, it is important to note that the respondents were split over whether or not it is their responsibility to help their students improve their lagging English abilities. While 50\% agreed that they had a responsibility to help improve their students English, 29\% disagreed illuminating that this is one issue where opinions are sharply divided. Interestingly, 70\% "felt that academic ideas can be explained more easily in English(Borg, 2015, p. 18)." This last observation should be one tool in ESL/EFL teacher's tool belts for encouraging young budding Kurdish scholars to either learn or improve their English skills and should be a topic for further research and discussion.

Regardless of the complicated issues and myriad of ideological and economic forces driving the adoption and growth of the English language and consequently EMI activities in Kurdistan and around the world, the most significant challenge to the success of EMI, according to the report, is, "the significant gap that is seen to exist between the proficiency in English students require and their actual ability in English(Borg, 2015, p. 28)." As a consequence of this major finding the British Council report offers a number of recommendations including several which will be familiar to many readers and critics. Among these are the 'oft' heard cries for more teacher training, support for students, international exchanges, academic collaboration, and, of course, more money, research, and conferences. All of these seem sound and necessary and one would think that they could be rather easily adopted by policymakers or determined teachers and students in individual institutions or by department heads of English departments across Kurdistan. However, the much more complicated recommendations to entertain, where real institutional changes can occur at a systemic level if adopted, are how to effectuate more informed policy decisions at the State and Ministry of Higher Education and Scientific Research (MHESR) level. Trying to implement these types of changes, at the so-called Macro level or the "seat of power", can be both problematic and occasionally damaging if not dangerous to one's career. This is as true in Kurdistan today, as it is in the United States or anywhere else.

\section{Considering the Big Picture}

As with the army of critics alarmed about the current direction of the United States' and international educational systems, Kurdistan to has its fair share of concerned observers calling for major reforms and a more democratic approach to the educational needs of the Kurdish people. In a recent August 17, 2017(Mohamad, 2017) article academics Abdurrahman Wahab and Aras Ahmed Mohamad criticized the increasingly centralized decision making processes they perceive to be negatively impacting Kurdish educational institutions. They cite institutional rigidity, bureaucratization, malpractice in teaching and administration, deficit thinking in policymaking and too much political meddling in academic decisionmaking as huge impediments to improving the system. In their stinging analysis, they write, "The educational system in Iraqi Kurdistan has become a medium for graduating an increasing number of youth with diplomas that little value beyond the region's problematic system of public employment, which does not require clear standards of academic value, merit, or skills."

At the classroom level they report about a national curriculum devoid of critical content chained to such practices as rote memorization and "indoctrination" where there is little, if any, focus on artistic innovation and scientific ambitions--which is particularly sad when you consider that Kurdistan today is the home of so many burgeoning worlds recognized artists and has a long history of poetry, drama, and storytelling. Like many critics in the West, Muhammad and Wahab are critical of these curricula omissions and with too much 
emphasis placed on final standardized examinations. As with other systems around the world like in England, Finland, and Korea, many Kurdish students futures are inexorably linked to these types of high stakes tests (Turner, 2014). In Kurdistan, as in other parts of the world, it is not uncommon to find once truly motivated students' lives destroyed over a point or two on one of these types of testing instruments.

For Mohamad and Wahab the centralized system of admissions for Kurdish universities based solely on student's final grades on the "baccalaureate degree" needs to be dumped into the ash bin of history. With all of the educational problems facing American institutions "underachieving" students in the United States still have several ways to improve their test scores, be reconsidered for university admission, enroll in Community Colleges, or seek alternative routes to achieve their life goals. Some of these types of avenues provide ample examples of educational alternatives for Kurdish policymakers. How one or many go about influencing the types of changes Mohamad and Wahab propose at the Macro or "seat of power" level in Kurdistan are topics for later critiques and analysis. But, these considerations and an understanding of these types of systemic institutional problems cannot be overlooked even when considering curriculum changes at the classroom or department level for those teachers and their students who are truly motivated to improve students English language proficiencies in their English classes or EMI classrooms. However, merely complaining about the problems or, as they say in America, "passing the buck" on to superiors or shirking any responsibility for becoming the change that teachers and students would like to see is simply not good enough. If we consider that the main finding of the British Council's survey is that the majority of students in EMI classes are not adequately prepared to study in English, coupled with the fact that these same students have had ESL/EFL types of classes for 12 years in Kurdish public schools then something, surely, is amiss. With the British Council's survey analysis in mind combined with the broader and sharper criticisms of people like Muhammad and Wahab then it becomes imperative to try and put into context what types of practical steps or actions individual instructors and their respective departments, schools, or institutions might take upon themselves in an effort to improve their overall ESL practice.

Working Toward a Local Solution: In some of Thornbury's early analysis for why Dogme types of nonmethod/methods were needed in successful EFL practice, he noted how many failing programs were literally drowning in an "embarrassment of resources" and "an over-dependence on manufactured materials." He cited how this "single-minded fixation on these materials" ran counter to the "expressed desire of teachers and learners to create more opportunities for 'real language use' in their classrooms." Moreover, these mostly grammar focused teaching systems produced stale classroom environments and that the western-centric textbooks used for instruction lacked cultural relevance for the students. (Thornbury S. , Dogme: Dancing in the Dark, 2005). In a number of interviews with Kurdish English language teachers at both public schools and universities as well as with college and public school students studying English throughout Kurdistan, it has become abundantly clear that the Kurdish ESL/EFL system is complete with many of the shortcomings that Dogme proposes to interrogate. One Kurdish elementary school teacher interviewed for this critique Sirwan Abdulrahman Rwanduzi reported how he regularly deals with an overcrowded classroom and still manages to teach 5 different classes for 40 minutes every day. Sirwan teaches at the Danai Scientific High School in the Soran area to over 125 students in grades 10-12. In writing about his many responsibilities and curriculum targets he reports, "I should teach all the subjects related to English grammar including (tenses, prepositions, relative clause, report statement, passive, advise, certain possibility, suggest, conditionals, model verbs, cause, and effects)." Moreover, he says he has to teach literature, reading, story, paragraphs, conversation, and speaking. He reports that on top of this battery of lessons he is required to write yearly, monthly, weekly and daily teaching plans. In spite of all of these demands and responsibilities this teacher believes that he has been relatively successful in teaching the English language to many of his students, especially the highly motivated ones, and credits in large part his own proficiency in the language and his dedication to his students and EFL practice for his positive results. Sirwan also manages a FaceBook page called English Teachers in Kurdistan which has a following of over 8,000 regular viewers.

However, this teacher is also quick to point out that the curriculum is extremely centered on grammar and strict adherence to the textbook Sunrise which is used by the majority of Kurdish schools. Moreover, he says that although Sunrise is theoretically a Communicative Language textbook many of its lessons and exercises fall short for his Kurdish students. Like most texts, this one is also very western-centric and has more than its fair share of critics. For example, in his 2015 study (Sofi-Karim, 2015) entitled "the English Language 
Teaching in the Kurdistan Region of Iraq" Mahdi Sofi-Karim offers an exhaustive in-depth analysis of the present curriculum in Iraqi Kurdistan and in particular focuses on the use of the textbookSunrise. Anyone interested in learning more about this text's inadequacies specifically in relation to Kurdistan should read the entire study. However, suffice it here to say that Sofi-Karim's central conclusion was that "The English syllabus Sunrise is not effective and fails to meet the needs of the Kurdish English learners in KRI [Kurdish Region of Iraq] (Sofi-Karim, 2015, p. 2)."

It is also important to note that both Sofi-Karim and Sirwan Abdulrahman Rwanduzi along with dozens of other teachers and students interviewed for this critique acknowledge that many English language teachers in Kurdistan are not adequately trained and lack many of the skills to be successful. Sofi-Karim writes "The curriculum of the English teacher colleges does not provide adequate courses focusing on the English language teaching methods and there is an insufficient number of English teachers trained in real classroom settings (Sofi-Karim, 2015, p. 2)." So, as not to belittle the point, all of these short-comings about the present state of ESL/EFL in Kurdistan are well known by everyone participating in the ESL/EFL project. They are talked about quietly in halls and offices, as well as in classrooms and cafeterias. Moreover, they are acknowledged by policy makers and decision makers who continue to perpetuate the same system without serious critique or efforts at reform. In addition, the literature about the system's problems is also a legend and there is plenty of finger-pointing and blame to go around. Although the scholarly criticism is important and should be encouraged, the finger-pointing and blame game is unproductive at best and literally immobilizing at worst. Nevertheless, as a consequence, for anyone truly interested in trying to improve the system the next step becomes to ask the questions "What can I do about it?" and "How do "I" become the change "I" want to see?"

\section{Making a Case for Dogme "Lite" in Kurdistan}

When Thornbury penned his Dogme ELT article back in 2000 he ignited a conversation among ESL/EFL professionals and practitioners that was long overdue and that has led many in the field to ask new and important questions and to very critically exam their own practices and the practices of the institutions where they work. Hopefully, too, along the way the conversation and deep-analysis have helped enlightened teachers improve the English speaking skills and abilities of many students. It is in this same spirit of questioning and visioning a better system that I too have penned this critique and offer my own call for a new Dogme effort in Kurdistan today. I have called this "Dogme Lite" and in the following pages will explain my thinking and offer some recommendations for consideration. First of all, trying to initiate change and choose a new path is not easy-regardless of where you are in the world or whatever it is you are wishing to change. I know this first hand from years of experience "tilting at windmills" and has won a few but losing many more. Moreover, it is critical to know that trying to effect major positive institutional change normally happens in one of two ways. It is either imposed from the top down by an enlightened leader or it happens from the bottom up after a long slow slog by organizing and achieving small victories. The bottom-up approach can take years - to be ready for the long haul. However, in the case of trying to implement a scaled-down version of Dogme ideas into the existing Kurdish school curriculum might actually be aided by the Iraqi Curriculum Framework adopted by academics across Iraq, including many in Iraqi Kurdistan, in 2012.(UNESCO, 2012)For individual teachers or instructors who are interested in trying something new in their curriculum, like a Dogme "Lite" approach, they can turn to the major platforms in the Framework and use them to bolster their argument with superiors or colleagues.

In general terms, the curriculum framework espouses values and principles which could arguably be interpreted to embrace innovation and change. In fact, many of the values and principles postulated echo the very concerns that Dogme raises about existing "western" centric texts not being culturally sensitive or relevant to their targeted learners. For example, in the Framework it clearly states that curriculum materials should "Be relevant to students' lives and their learning and development needs" and "Reflect the culture and local content", as well as "Allow national expectations to be set in a local context (UNESCO, 2012, p. 14)." All of these sentiments are reflected in the "tenants" of Dogme and have been commented on by Thornbury and other "dogmatists". Moreover, the Framework states that teachers should "Create an enabling learning environment and encourage active learning, including the use of new technology in education." Furthermore, as if written by a Dogme exponent or acolyte of Paulo Freire the guidelines suggest that teachers "Engage the 
learner in social dialogue and collaborative learning" not to mention "Enable learning to be personalized and enjoyable and encourage independence and self-management of learning." All Kurdish teachers, especially ESL/EFL teachers, who might be a little wary of current practice should read this document and consider its implications.

In particular, when it comes to language teaching and language curriculums the Framework offers, still yet, further openings for innovation and experimentation. One recent evaluation of the Framework and its significance to language teaching in Iraqi Kurdistan clearly shows that the document could be interpreted to support Dogme types of innovative curriculums or strategies within the existing ESL teaching program. The 2015 study authored by Hamsa Hameed Ahmed, Fariza Puteh-Behak and Harison Mohd Sidek states, "The underpinning principles of teaching and learning as recommended by the Iraqi Curriculum Framework are learner-centeredness, interactive teaching and learning, connecting theory and practice as well as new things with the learner's experience and environment(Hamsa Hameed Ahmed, 2015)." Specifically, this study substantiates that the Sunrisetextbook series currently in use today in Kurdistan is primarily a communicative language teaching curriculum. This is important to note because it has implications for the introduction of Domestique "exercises", ideas and lessons into the existing curriculum.

In fact, the relationship between Dogme and Communicative Language Teaching cannot be understated. In his own words recalling the inception of Dogme Thornbury states that his reforming ideas, "grew out of a frustration with the way the so-called communicative approach seemed to have been betrayed and hi-jacked by globalized ELT publishing initiatives (Thornbury, 2009)." More to the point Thornbury recalled that he wanted to "de-toxify" language teaching away from its encumbrance on published materials like Sunrise and return it to its Communicative roots by restoring the "Big C" in the Communicative Approach. Towards real classroom and pedagogic solutions, Thornbury encouraged his trainees and others to, as he puts it, "make more out of less" and "cultivate a learning context that foregrounded what the learners bring to the classroom (Thornbury S. , Scott Thornbury, 2009, p. Item 5)." In short, one could, in my estimation, easily argue that Dogme is simply buttressing the Communicative Language Approach and reminding teachers that in pursuing their goals they can deviate from the regimentation and dreariness of the curriculum on a regular basis and not be at risk of abandoning their overall mandate to "teach the curriculum." In fact, I believe that trained practitioners can "Dogmetize" their existing curriculum whether it is Sunrise, Face-to-Face or a host of the others present in use in Kurdistan. Thus, enters Dogme "Lite".

Taking the first steps: In proposing a Dogme "Lite" method with the "Big C" back in the Communicative process I am neither advocating abandoning the course textbook nor hoping for a bonfire of such curricula as the visionary New Zealand educationalist Sylvia Ashton-Warner reported enjoying when she decided to dispense with all of the unnecessary 'accoutrements' cluttering up her classroom. (Thornbury, 2009, p. 12) In fact, the very first step in the process I am proposing is that all English teachers in Kurdistan need to buy a copy of Thornbury and Medding's Teaching Unplugged or download the Pdf that is available on the internet and immediately set about reading it. Moreover, I believe that it is necessary to begin a conversation across the country, particularly focused on teachers and students who have already expressed interest in exploring alternatives to the present system. For starters, FaceBook sites like English Teachers in Kurdistan maintained by Sirwan Abdulrahman Rwanduziwould be a good place to begin. These initial conversations could be followed up by local and regional meetings culminating in a first "annual" Dogme/Unplugged Conference.

Second: English teachers wishing for change can take the "revolutionary" first step and begin "Dancing in the Dark(Thornbury S. , Dogme: Dancing in the Dark, 2005)." They can decide to try and become the change they want to see and deviate at least once, if not twice, a week from their textbook syllabus and go about creating a classroom environment and dynamic that is "conducive to interactive talk" and flexible enough to take advantage of conversations that emerge incidentally as they occur in class. And, then the teacher needs to be both a participant in such conversations and able to provide the necessary "scaffolding" to support the talk in English (Thornbury, 2009, p. 21). One big hurdle for this to occur, which Thornbury recognized in his early writings, is that teachers will have to overcome their fear and be willing to take the risk of "just being another person in the room (Thornbury S. , Dogme: Dancing in the Dark, 2005, p. 3)." Moreover, teachers will have to be patient and like novice farmers who regularly check their seedlings avoid the temptation to overwater or do too much tilling. 
Third: In following the directive to free the classroom as much as possible from third-party imported materials, teachers need to do everything they can to "Kurdify" the proscribed materials they plan to use. This might mean a little more time and preparation but exercises as simple as "Do you like dolma more than Kuba?" and then asking the students "Bochi" or "Why" and exercises exploring the student's experiences in Kurdistan with questions and lessons like "Have you been to Chavyland?" or "Have you been to the Mall in Erbil? "can make a world of difference. In a recent experimental summer long course for elementary students at the Shekkar Center in Soran, I worked with a team of young university English students to "Kurdify" as many materials as possible. We created PowerPoint slide presentations using Kurdish images, places, themes, and names as well as created materials about the student's neighborhoods and about Kurdistan in general. In addition, we wrote stories using all of the student's names with information that they had provided about themselves in previous exercises. These types "materials-light" lessons oriented to the learner's needs and interests are focused on creating the environment and setting up activities where emergent language can occur. These types of lessons/activities are chronicled in Teaching Unplugged (Thornbury, 2009) and the book also provides teachers with a considerable amount of the theoretical underpinnings they will need to more fully inform their work.

Fourth: Another thing that elementary and high school teachers might consider is how to involve students studying English from the universities in their area to help them with their oversized classes. If there is one thing I have learned it is that there is a huge "pool" of energetic, knowledgeable, and willing young university students studying English in Kurdistan who want to have the opportunity to teach their fellow Kurds the English language. And, unfortunately, I am not aware of any programs that could tap this amazing human resource and help address classroom overcrowding and also provide learning and teaching opportunities for university students.

\section{Conclusion}

At the end of Thornbury's 2005 article (Thornbury S. , Dogme: Dancing in the Dark, 2005) where he proposed writing a textbook about Dogme he asked whether or not there were "Any takers" out there to help him craft a book and chronicle their Dogme experiences. With this critique, I too am asking if there are any English language teachers in Kurdistan who want to see a change and who might be willing to become the change themselves that they would like to see. Can such a process as Dogme "Lite" help improve the English language abilities of the students entering those EMI classrooms evaluated by the British Council? Can Dogme "Lite" ideas be used at universities in Kurdistan to help improve the student's communicative language skills who are studying English? If you agree with the words first written by Thornbury in 2000, "That it is high time Dogme-type principles were applied to the [EFL] classroom" then it is time to get to work. Any takers?

\section{References}

Borg, S. (2015). English Medium Instruction in Iraqi Kurdistan. London: British Council.

Coskun, A. (2016). Dogme ELT: What do teachers and students think? ResearchGate.

Hamsa Hameed Ahmed, F. P. B. (2015). Examining EFL Secondary Reading Curriculum in Iraqi Kurdistan: A Review. Journal of Applied Sciences, 3, 377-391.

Meador, D. (2016). Solutions for Teaching in an Overcrowded Classroom. Retrieved August 3, 2017, from ThoughtCo.: https://www.thoughtco.com/teaching-in-an-overcrowded-classroom-3194352

Mohamad, A. W. (2017). Future of Kurdish Education Hangs in Uncertainty. Fair Observer.

Rahul, D. (2015). A Critique on Dogme ELT. ResearchGate.

Sofi-Karim, M. (2015). English Language Teaching in the Kurdistan Region of Iraq. Webster Grove: Webster University--ResearchGate.

Thornbury, L. M. (2009). Teaching Unplugged: Dogme in English Teaching. Peaslake: Delta Publishing.

Thornbury, S. (2000). A Dogma for EFL. International Association of Teachers of English as a Foreign Language, 2.

Thornbury, S. (2005). Dogme: Dancing in the Dark. Folio, pp. 3-5. 
Thornbury, S. (2009). Scott Thornbury. Retrieved August 16, 2017, from Delta Publishing Blog.: http://www.deltapublishing.co.uk/author/scott-thornbury

Turner, C. (2014). U.S. Tests Teens A Lot, But Worldwide, Exam Stakes Are Higher. Retrieved August 7, 2017, from NPR: http://www.npr.org/2014/04/30/308057862/u-s-tests-teens-a-lot-but-worldwideexam-stakes-are-higher

UNESCO. (2012). Iraqi Curriculum Framework. Amman: United Nations Educational, Scientific, and Cultural Organization. 